\title{
Modeling The Effect of Nitrogen Dioxide Produced In Shazand Power Plant Upon Air Pollution In Arak, Iran Using Sentinel-5 Satellite Data
}

Mohammad Amin Ghannadi

Arak University of Technology

Matin Shahri ( $\nabla$ shahri@arakut.ac.ir)

Arak University of Technology https://orcid.org/0000-0002-1544-6414

Amir Reza Moradi

Arak University of Technology

\section{Research Article}

Keywords: Sentinel-5 satellite images, air pollution, NO2, remote sensing, power plant

Posted Date: May 27th, 2021

DOI: https://doi.org/10.21203/rs.3.rs-513278/v1

License: (c) (i) This work is licensed under a Creative Commons Attribution 4.0 International License.

Read Full License 


\section{Modeling the Effect of Nitrogen Dioxide Produced in Shazand Power Plant upon Air Pollution in}

Arak, Iran Using Sentinel-5 Satellite data

Mohammad Amin Ghannadi ${ }^{1}$, Matin Shahri ${ }^{* 2}$, Amir Reza Moradi ${ }^{3}$

1- Assistant Professor, Department of Geoscience Engineering, Arak University of Technology, Arak, Iran

2- Assistant Professor, Department of Geoscience Engineering, Arak University of Technology, Arak, Iran

3- Assistant Professor, Department of Geoscience Engineering, Arak University of Technology, Arak, Iran

* Corresponding author at Department of Geoscience Engineering, Arak University of Technology, Arak, Iran.

Phone: +98 8633400801, Email: shahri@arakut.ac.ir 


\begin{abstract}
Nowadays, air pollution and its negative effects on human health is regarded as one of the most fundamental problems in the world. Iran as a developing country also deals with the issue of air pollution. Nitrogen dioxide (NO2) as one of the air pollutants leads to serious damage to the human respiratory system. The power plants are recognized as one of the main sources of producing NO2. In this research, the effect of NO2 produced in Shazand power plant on the air pollution in Arak metropolitan area, as one of the most polluted cities in Iran will be investigated using a third-order rational mathematical model. Sentinel-5 satellite images have been applied to monitor NO2 in the study area during the two years 2020-2019. The results indicate that the proposed model has been successful to model the relationship between the amount of NO2 produced in Shazand power plant and its propagation in Arak city using a set of control points with the values of RMSE, MAE and $R^{2}$ equal to $2.1 \times{ }^{6-1} 10,1.3 \times{ }^{6-10}$ and 0.99 respectively. The results of model validation using check points with the values of RMSE, MAE and $R^{2}$ equal to $1.7 \times{ }^{6-} 10,1.1 \times{ }^{6-} 10$ and 0.99 respectively indicate that the model can also be applied to any data location in the study area.
\end{abstract}

Keywords: Sentinel-5 satellite images, air pollution, NO2, remote sensing, power plant 


\section{Introduction}

Air pollution is now considered to be one of the world's most significant issues and plays a crucial role in global climate change and premature deaths worldwide. According to the World Health Organization (WHO), air pollution is recognized as the world's most important death threat, causing about 3 million deaths worldwide annually (Lelieveld, Evans et al. 2015). While more than half of all deaths occur in developing countries (more than half a million in India only) (Chowdhury and Dey 2016, Ghude, Chate et al. 2016), it can be seen that air pollution also contributes to premature death in some developed countries (e.g. the United States) (Caiazzo, Ashok et al. 2013). Factors such as population growth and the increase in number of vehicles, as well as increasing industrialization and energy demand can be mentioned as the most probable reasons that cause pollution in many metropolitan areas. It is therefore important to accurately evaluate the quantity the amount of air pollutants with acceptable spatial and temporal resolution at local, regional and global levels in order to determine their distribution and effect, and to provide solutions for managers at different spatial resolutions (Saxena and Naik 2018).

In general, there are different types of pollutants in the atmosphere, the serious effects of which on air quality, environment, human health and climate have become one of the most important concerns in the $21^{\text {st }}$ century. Sulfur dioxide (SO2), carbon dioxide (CO2), carbon monoxide (CO), nitrogen dioxides (NO2), ozone (O3), methane (CH4), unstable organic carbon, chlorofluorocarbons and suspended particles or aerosols can be regarded as the most important air pollutants (Saxena and Naik 2018), among which, nitrogen oxides (NOx) is considered as one of the most toxic gases (Dickerson, Anderson et al. 2019, Park, Shin et al. 2020). Every year, millions of tons of nitrogen dioxide (NO2) and nitrogen oxide (NO), are produced by different human activities, especially by the consumption of fossil fuels in high temperatures. Nitrogen dioxide produces nitric acid in combination with humidity which and causes severe metal decay. These gases also contribute to the formation of smog and acid rain (Park, Shin et al. 2020) Nitrogen oxides (NOx) are also known as "indirect greenhouse gases" because they enter the upper troposphere (Grewe, Dahlmann et al. 2012, Finney, Doherty et al. 2016) through thunderbolt and play an important role in global warming by producing ozone (Grewe, Dahlmann et al. 2012, Finney, Doherty et al. 2016). These factors have adverse effects on the human respiratory system and will also have many negative effects on plant growth (Kim, Heckel et al. 2006, Kampa and Castanas 2008).

Because of the ability to generate continuous temporal and spatial data, using tools and technologies based on remote sensing is extremely important among the numerous methods of monitoring air pollution. Information about air pollutants is transmitted through electromagnetic radiation in this process, and vertical profile measurements, as well as information about air pollutants, are reported with an appropriate spatiotemporal resolution (Saxena and Naik 2018). Monitoring of air pollutants with the help of satellite and remote sensing provides an appropriate platform for understanding the current state of air quality and future climate change in a global scale. The accurate monitoring of pollutants is also important due to considerations such as chemical composition, lifetime, emission sources etc. (Saxena and Naik 2018).

The Sentinel-5 satellite and its sensor, TROPOMI, are among the satellites capable of capturing pollutionrelated data and have a high capability in imaging and tracking different types of gases and contaminants such as ozone, formaldehyde, sulfur dioxide, methane, carbon monoxide, aerosols, and nitrogen dioxides. One of the most significant benefits of Sentinel-5 satellite imagery in the process of pollution monitoring is that it allows for the collection of data from a high altitude at a particular location, which can be useful in determining the spatial distribution of pollutants. However, there are restrictions in data collection using Sentinel-5 such as low number of observations during the day as well as the presence of clouds in some observations. Due to the rapid distribution of contaminants in the atmosphere, monitoring with such images may not be precise enough (Vîrghileanu, Săvulescu et al. 2020). In certain cases, the effects of pollution on human health are modeled and assessed using indirect information from pollutants, while the TROPOMI sensor can directly provide the data (Lorente, Boersma et al. 2019). Review of past studies indicates the success of applying Sentinel-5 satellite images in monitoring sulfur dioxide (Hedelt, Efremenko et al. 2019, 
Theys, Hedelt et al. 2019) carbon monoxide (Safarianzengir, Sobhani et al. 2020) Formaldehyde (Vîrghileanu, Săvulescu et al. 2020), Ozone (Quesada-Ruiz, Attié et al. 2020) NO (Lorente, Boersma et al. 2019) and NO2 (Ialongo, Virta et al. 2020, Omrani, Omrani et al. 2020, Shikwambana, Mhangara et al. 2020, Vîrghileanu, Săvulescu et al. 2020).

Industrial activities are a significant cause of $\mathrm{NO} 2$ emissions in the atmosphere. As a result of the Covid-19 virus pandemic, industrial activity has decreased, and consequently, the $\mathrm{NO} 2$ levels have decreased significantly (Vîrghileanu, Săvulescu et al. 2020). Studies can be mentioned in which the role of pandemy of Covid-19 virus in changes the amount of pollutants (particularly NO2), using TROPOMI sensor images have been investigated (Bauwens, Compernolle et al. 2020, Cameletti 2020, Mesas-Carrascosa, Pérez Porras et al. 2020, Ogen 2020, Stratoulias and Nuthammachot 2020).

Considering the importance of pollution monitoring and especially $\mathrm{NO} 2$ as one of the most important and harmful air pollutants and the importance of investigating it in industrial metropolitan areas as well as the capability of remotely sensed technologies and Sentinel-5 satellite, in this study, Arak in Markazi province has been selected as the study area. Among the metropolises in Iran, the presence of factories and industries in Arak such as Shazand power plant, refinery and petrochemical industry as well as Iran Aluminum Company and Mashin-Sazi in Markazi Company has made Arak metropolitan area as one of the largest industrial pole in the country. Shazand power plant is known as one of the main sources of NO2 in the study area. Therefore, the issue of monitoring gases and air pollutants in order to make appropriate decisions to reduce or eliminate the negative impacts in the study area is a permanent concern of urban managers. Accordingly, this study, aims to construct a mathematical model to establish a relationship between the concentration of $\mathrm{NO} 2$ in Shazand power plant and other determined locations at specific times in Arak during two-year period of study 2019 - 2020. This approach allows for easy measurement and evaluation of NO2 in the study area, and the results help managers to provide solutions at different levels. The importance of the issue is yet more since according to investigations and previous studies, Shazand power plants plays a critical and direct role to increase the amount of NO2 and SO2 (Shikwambana, Mhangara et al. 2020). In this paper, primarily, the study area and the process of data collection are described and then, the suggested model for establishing the relationship between the concentrations of NO2 in Shazand power plant and other locations is introduced. Then, the results of the implementation of the proposed model will be presented in the next section.

\section{Methodology \\ 2.1. Study Area}

The study area for monitoring NO2 and implementing the proposed model is Arak, which is located in Markazi province in northwest $\operatorname{Iran}\left(34.0954^{\circ} \mathrm{N}, 49.7013^{\circ} \mathrm{E}\right)$ and is close to Miqan wetland, with its average altitude 1743 meters above sea level and covers an area of around 560 square kilometers. The study area has been illustrated in Fig 1. The Shazand power plant, which is one of the major sources of NO2, is about 20 kilometers southwest of Arak. This thermal power plant with four production units and a capacity of 1300 megawatts is one of the most important thermal power plants in Iran. 


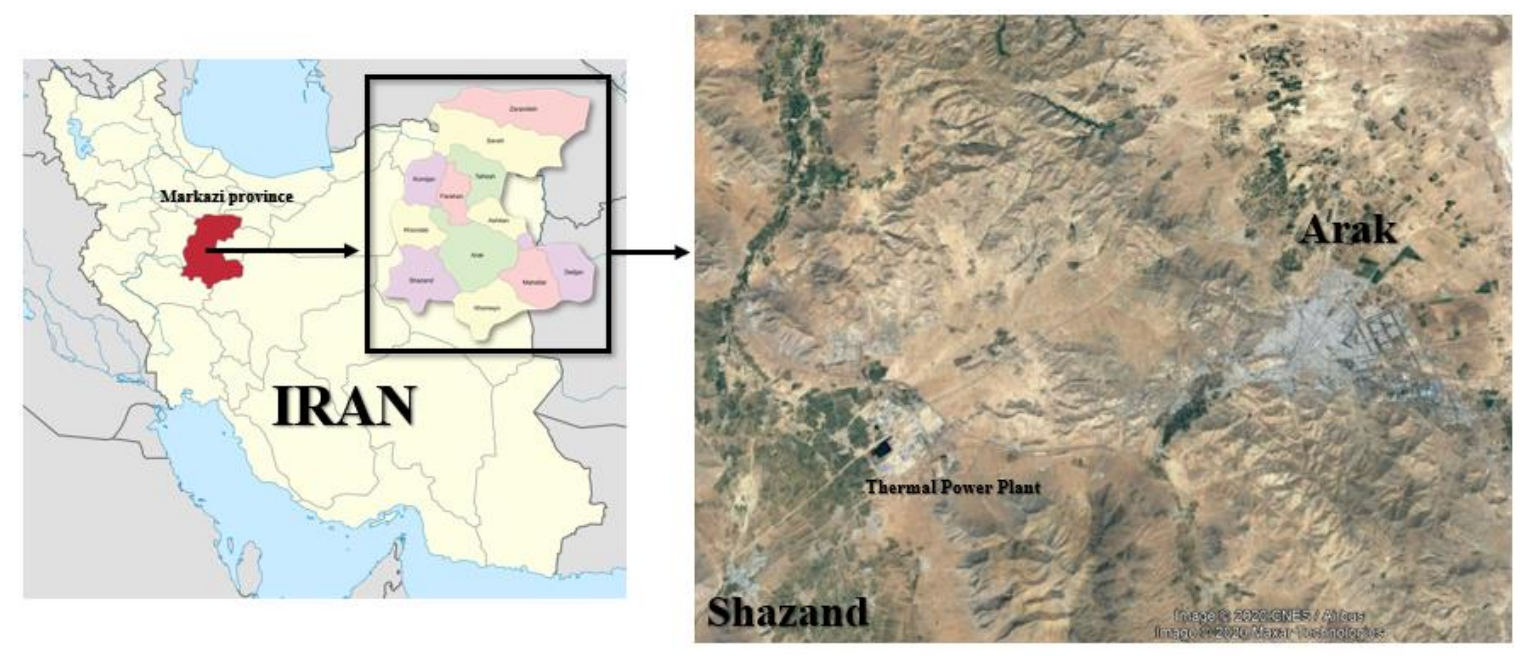

Fig 1 Overview of Study area, Arak, Markazi Province, Iran

\subsection{Data Preparation}

In order to monitor the amount of NO2 in this research Sentinel-5, TROPOMI level-3 (L3) products have been employed. Sentinel-5 is the Copernicus mission's first satellite and one of the most effective in the field of atmospheric monitoring. Sentinel-5 contains a sensor called TROPOMI with the ability of recording ultraviolet radiations. One important mission of Sentinel-5 is to ensure of the continuity of data collection relating to previous (SCIAMACHY, GOME-2, OMI and Envisat) and future missions (de Vries, Voors et al. 2016). Every day, TROPOMI collects data on the Earth's atmosphere with a spatial resolution of $7 \mathrm{~km}$ $\times 3.5 \mathrm{~km}$, which is 13 times greater than OMI (Shikwambana, Mhangara et al. 2020). TROPOMI images have eight bands that include ultraviolet (UV), near-infrared (NIR), and short-wave near-infrared (SWNIR) wavelengths (SWIR) (Lorente, Boersma et al. 2019) TROPOMI is capable of imaging and monitoring a large number of pollutants with three types of processing including NRT (near real time), OFFL (Offline), and reprocessing. For NRT processing the availability of products must be within 3 hours after sensing, while the availability of products for OFFL (Offline), and reprocessing is about 12-hours to 5 days after sensing (Shikwambana, Mhangara et al. 2020). The NRT tropospheric NO2 concentration band was used in this analysis to measure the gas concentration in the troposphere. To study the general trend of spatio-temporal changes of NO2 in the study area, 1460 of daily satellite images have been employed from the beginning of 2019 to the end of 2020.the images have also been obtained from different orbits.

\subsection{Model Structure}

As stated earlier, the purpose of this study is to model the effect of NO2 produced in Shazand power plant on air pollution in Arak metropolitan area. In order to determine a mathematical model that can establish a spatio-temporal relationship between the concentrations of NO2 produced in the power plant and different parts of the study area, a third-order rational equation is proposed. The model is proposed due to its flexibility in the process of modeling complicated phenomena (Sohn, Park et al. 2005). The next step is to determine the most efficient and influential parameters in determining NO2 concentrations in various parts of the study area. As previously mentioned, the geographical location of each point, the time of pollution measurement (NO2 concentration varies depending on the day of the year), and, of course, the amount of gas produced (NO2 concentration in Shazand power plant) can be considered as essential factors influencing the concentration of such pollution (Bai, Tian et al. 2021). In the data analysis section, spatio-temporal changes in the concentration of $\mathrm{NO} 2$ in the study area within different times (specific months) have been examined. Following the determination of the model's independent variables, the third-order rational equation is suggested as follows: 


$$
\begin{gathered}
N O 2_{A r a k}=\frac{P 1\left(X, Y, T, N O 2_{T P P}\right)}{P 2\left(X, Y, T, N O 2_{T P P}\right)} \\
P 1\left(X, Y, T, N O 2_{T P P}\right) \\
=c_{0}+c_{1} X+c_{2} Y+c_{3} T+c_{4} N O 2_{T P P}+c_{5} X^{2}+c_{6} Y^{2}+c_{7} T^{2}+c_{8} N O 2_{T P P}^{2}+c_{9} X . Y \\
+c_{10} X . T+c_{11} X . N O 2_{T P P}+c_{12} Y . T+c_{13} Y . N O 2_{T P P}+c_{14} X^{3}+c_{15} Y^{3}+c_{16} T^{3} \\
+c_{17} N O 2_{T P P}^{3}+c_{18} X^{2} . Y+c_{19} X^{2} \cdot T+c_{20} X^{2} \cdot N O 2_{T P P}+c_{21} Y^{2} \cdot X+c_{22} Y^{2} T \\
\\
+c_{23} Y^{2} . N O 2_{T P P}+c_{24} T^{2} \cdot X+c_{25} T^{2} Y+c_{26} T^{2} \cdot N O 2_{T P P}+c_{27} N O 2_{T P P}^{2} \cdot X+c_{28} N O 2_{T P P}^{2} . Y \\
+c_{29} N O 2_{T P P}^{2} . T
\end{gathered}
$$

$N O 2_{\text {Arak }}$ represents the concentration of NO2 at any place in the study region as a function of location (X, $\mathrm{Y})$, time (T), and the concentration of NO2 at the Shazand power plant $\left(N O 2_{T P P}\right)$ in Equations (1) to (3). The coefficients of the rational equation are expressed by the values of $\mathrm{c} 0$ to $\mathrm{c} 58$, which must be calculated. Using Equation (1) to (3) and a set of control points (points at which, the concentration of NO2 is monitored to determine the coefficients of the proposed model), following equations can be considered.

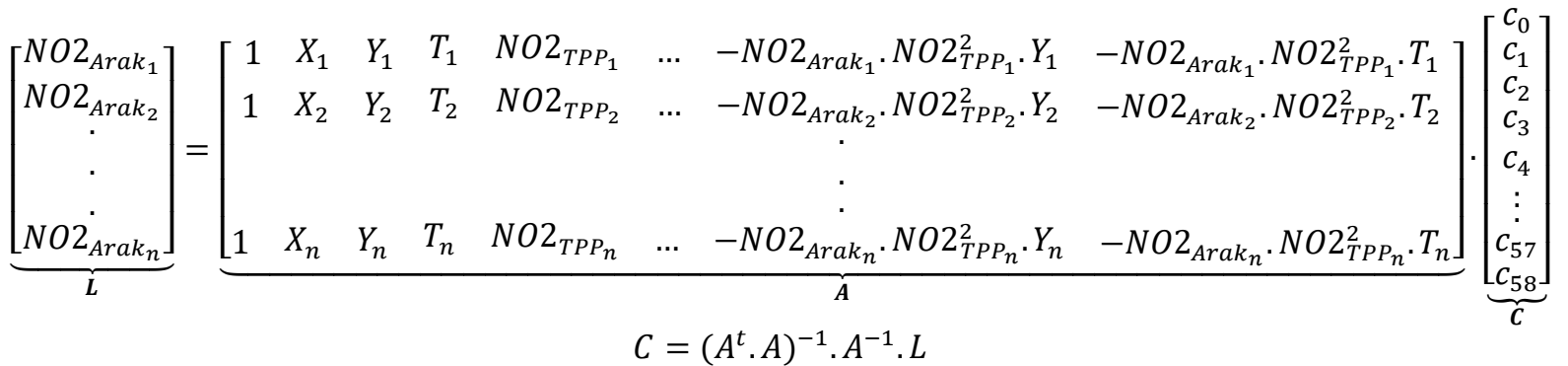

Since, there are n' control points observed during 24 months, the total number of observations is $n^{\prime} \times 24=n$. According to Equation (5), by determining the matrix C, it can be claimed that the connecting model is specified. In order to evaluate the accuracy and consistency of the proposed model, check points can be applied (points that have not participated in the model calibration process). After determining the proposed model by specifying the coefficients of the matrix $\mathrm{C}$, it is possible to calculate an estimated value of the concentration of pollutant by substituting the relating values of location, time and the amount of NO2 concentration relating to the check points in the resulting model (Equation (6)).

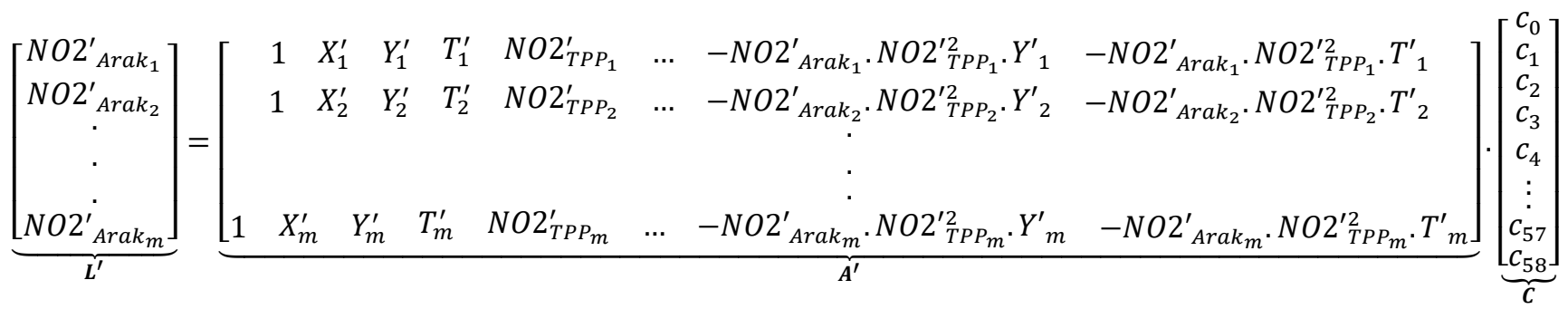

In Equation (6), $\boldsymbol{L}^{\prime}$ 'is the concentration of NO2 estimated by the proposed model per check point. In this case, $\mathrm{m}$ ' $\times 24=\mathrm{m}$, where $\mathrm{m}$ ' is the number of check points monitored for 24 months. These estimated values are compared with the corresponding observed values of known check points monitored previously, and consequently, the model error is determined. Equation (7) shows the calculation of the model error. 


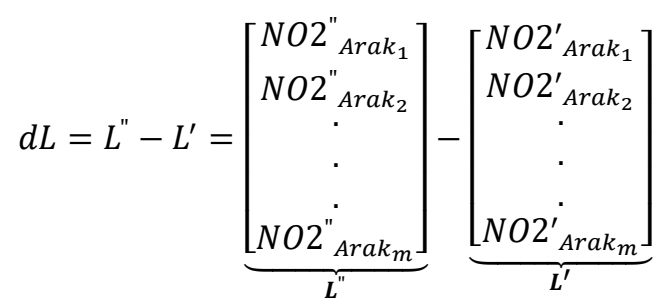

In Equation (7), $\mathrm{dL}$ is the error matrix of proposed model. The smaller $\mathrm{dL}$, the better the proposed model is able to establish the relationship between the concentration of NO2 produced in the Shazand power plant and the concentration of NO2 in different parts of the study area.

Goodness-of-fit criteria make the possibility of to compare how the models fit the data. In order to evaluate the accuracy of the model fitting as well as the validation of the model and its ability to estimate the values of the variable in other spatial locations, the statistical indices of root mean square error (RMSE), the mean absolute error (MAE) and Pearson correlation of coefficient have been applied (Vîrghileanu, Săvulescu et al. 2020) (Equation 8, 9 and 10).

$$
\begin{gathered}
R M S E=\sqrt{\frac{\sum_{i=1}^{n}\left(L_{i}^{\prime \prime}-L_{i}^{\prime}\right)^{2}}{n-1}} \\
M A E=\frac{\sum_{i=1}^{n}\left|L_{i}^{\prime \prime}-L_{i}^{\prime}\right|}{n} \\
R=\frac{\operatorname{Cov}\left(L^{\prime}, L^{\prime \prime}\right)}{\operatorname{var}\left(L^{\prime}\right) \operatorname{var}\left(L^{\prime \prime}\right)}
\end{gathered}
$$

In the above equations, $L^{\prime \prime}$ and $L^{\prime}$ are the concentration of monitored and estimated NO2. Also, $\mathrm{n}$ is the number of observations per control point (or check).

\section{Results}

In this study, in order to determine the coefficients of the proposed model, the concentration of $\mathrm{NO} 2$ for at specific points known as control points, have been monitored over a period of two years. Therefore, for each control point, 24 data, including the monthly concentration of NO2, are observed. These values are in fact those of $\mathrm{NO} 2$ Arak values in Equation (1) at different times per the locations of control points. In order to solve the problem, 15 control points have been applied and the values of NO2 concentration at each point per month have been observed ( 360 data in total). In addition, five points have been selected as check points to assess the accuracy of the proposed model. The distribution of control and c heck points in the study area have been illustrated in Fig 2. 


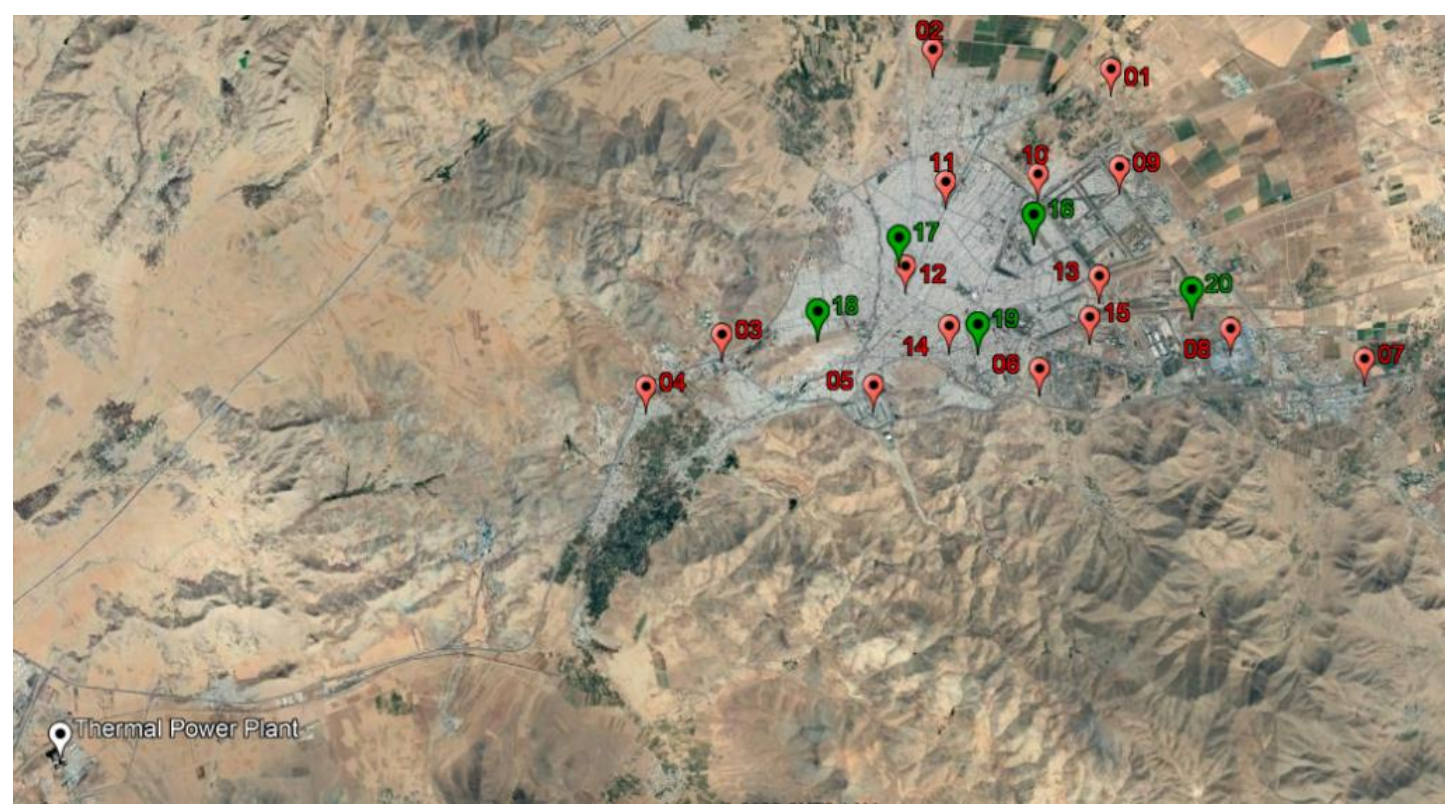

Fig 2 Spatial distribution of control and check points in the study area.

Fig 3 displays the maps relating to the spatial distribution of the medians of NO2 concentrations over the period of two years of research (2019-2020, including 24 months). When dealing with quantitative data, or when comparing the distribution of a variable in several populations is concerned, measures of central tendency such as median would be very helpful.

As shown in Fig 3, the distribution of NO2 is from southwest to northeast of the study area. However, it should be noted that the important role of wind direction in this area cannot be neglected. This partly confirms the hypothesis of the influence of $\mathrm{NO} 2$ resulting from Shazand power plant upon the pollution of Arak.

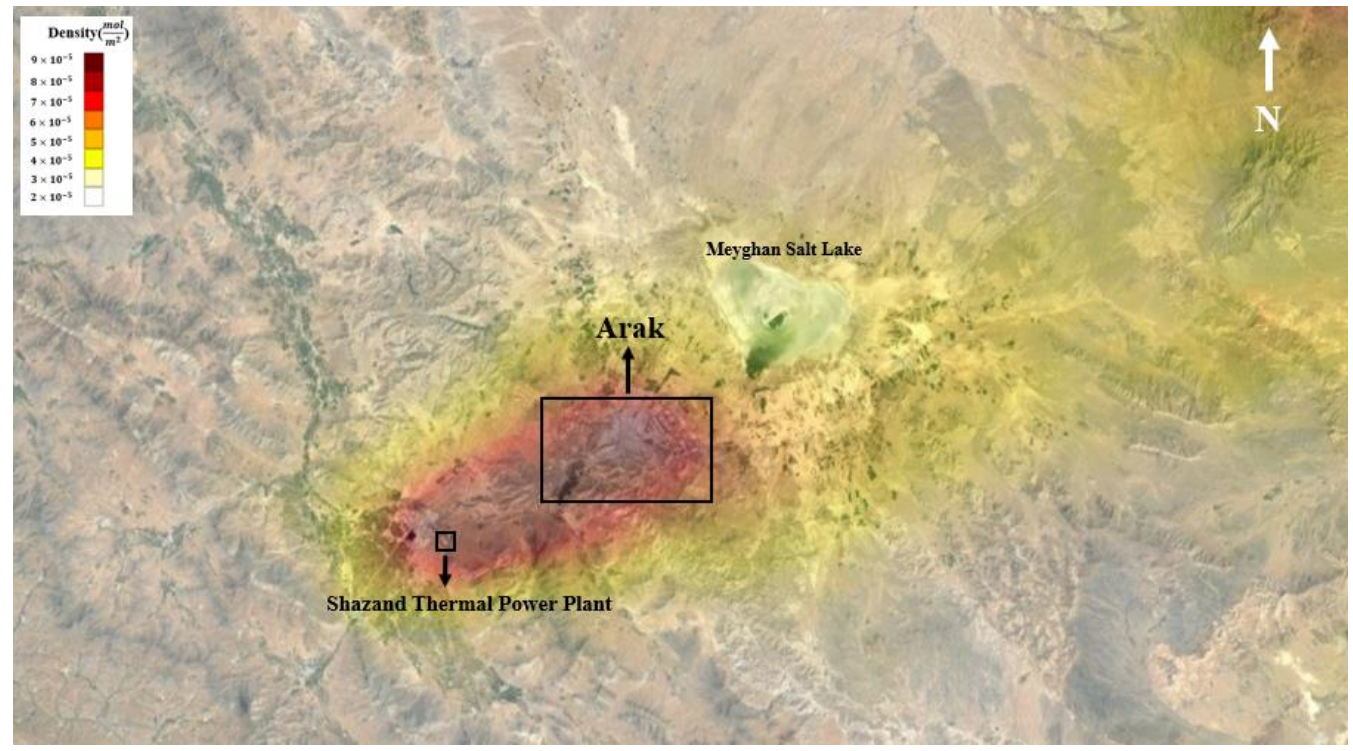

Fig 3 Variation of tropospheric NO2 distribution in the study area from January 2019 to December 2020 

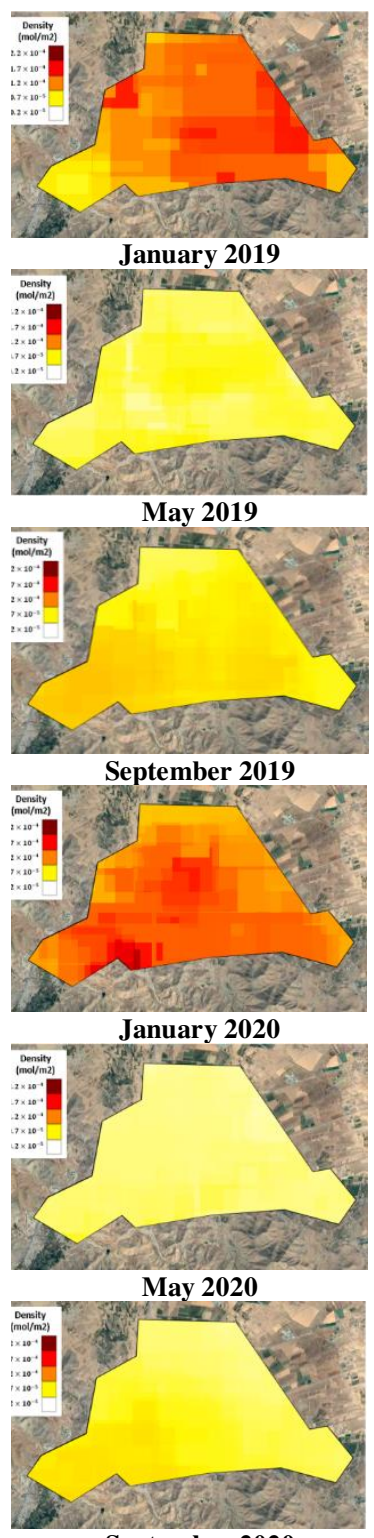

September 2020

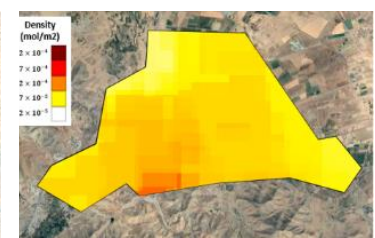

February 2019
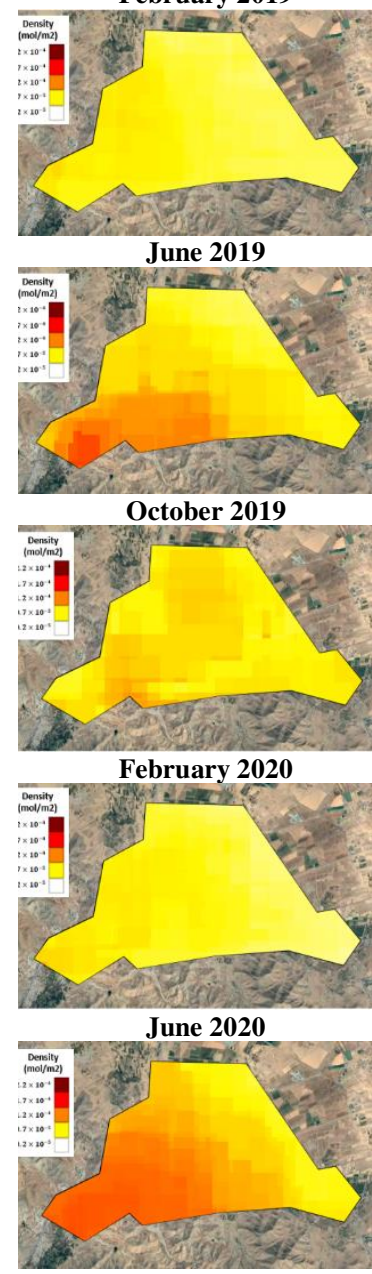

October 2020
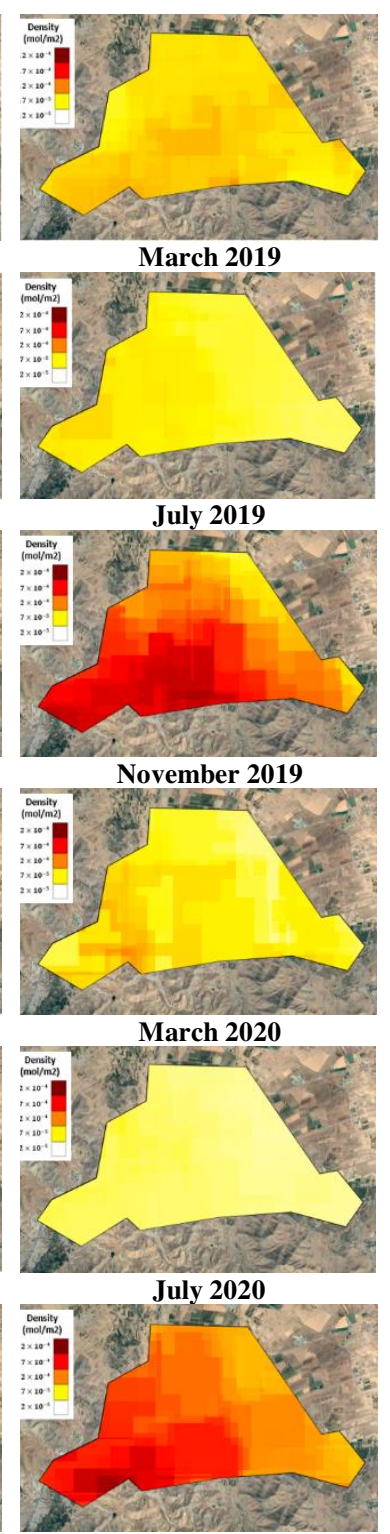

November 2020
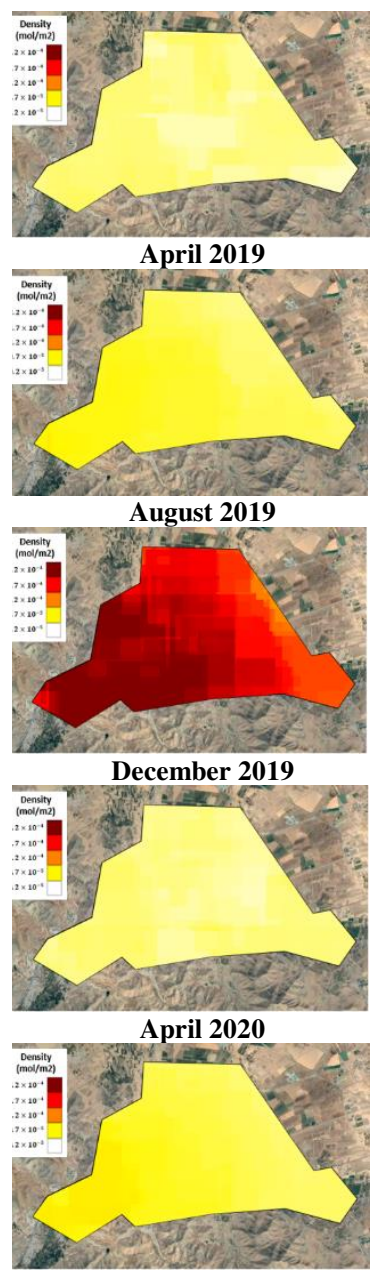

August 2020

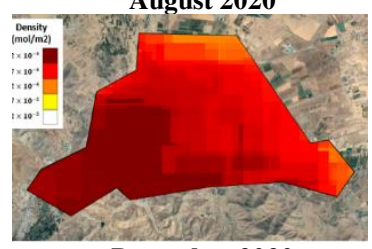

December 2020

Fig 4 The trend of spatial variation of concentration of NO2 in Arak from January 2019 to December 2020

Also Fig 4 shows the spatial variation of $\mathrm{NO} 2$ in the troposphere of study area for different months during a period of 2 years (beginning of 2019 to end of 2020). The figures indicate the considerable concentration of NO2 in some months of the year from the mid-autumn to mid-winter (November to January) compared to other months of the year, which is due to the phenomenon of inversion and concentration of pollution close to the ground. Accordingly, the significant decline of concentrating the NO2 during warm months of the year can be detected. It is also observed that, the air pollution in the southwestern part of study area is more than other places in most times of the year. This indicates that NO2 pollution is mostly concentrated in this part of the study area implying that an external factor can be considered as the source of such pollution.

Since, Shazand power plant can be considered as one of the sources of producing NO2 in the study area, the corresponding values at the geographical location of Shazand power plant have been explicitly investigated. Fig 5 and Fig 6 indicate the daily and monthly fluctuations of NO2 concentration monitored by TROPOMI images at the location of Shazand power plant during the period of two years of study. As can be seen, NO2 concentrations differ not only from month to month, but these variations are also detected within each month. 
Fig 5 also shows the increasing trend of producing NO2 in 2020 compared to 2019. Based on chart it can be inferred that the median values in the last months of the year are higher than other months. The figures also confirm that the time parameter plays a critical role in changes of concentration of $\mathrm{NO} 2$.

It is worth to note that the concentration of $\mathrm{NO} 2$ in our case study, Arak, does not show a significant change in 2020 compared to 2019. Due to the restrictions by government with the purpose of decline the trend of corona epidemic, vehicle movements and, as a result, traffic congestion have reduced in 2020 compared to 2019. However, month-by-month comparison of 2020 and 2019 reveals that NO2 levels have not decreased in 2020 compared to 2019 (Fig 4).

Therefore, it is not an exaggeration to claim that Shazand power plant has a decisive role in the air pollution of the city of Arak in terms of increasing the concentration of NO2. As indicated in Fig 5, not only the production of NO2 in 2020 has not declined due to the Covid-19 outbreak, but also has significantly increased. Therefore, numerical modeling of the effectiveness of NO2 in Shazand power plant in the process of estimating the concentration of such pollutant in Arak can be very helpful and appropriate.

As mentioned earlier, the proposed model as a third-order rational model was calibrated using NO2 data per month over a two-year period (2019-2020), associated with 15 control points (360 observations). The result

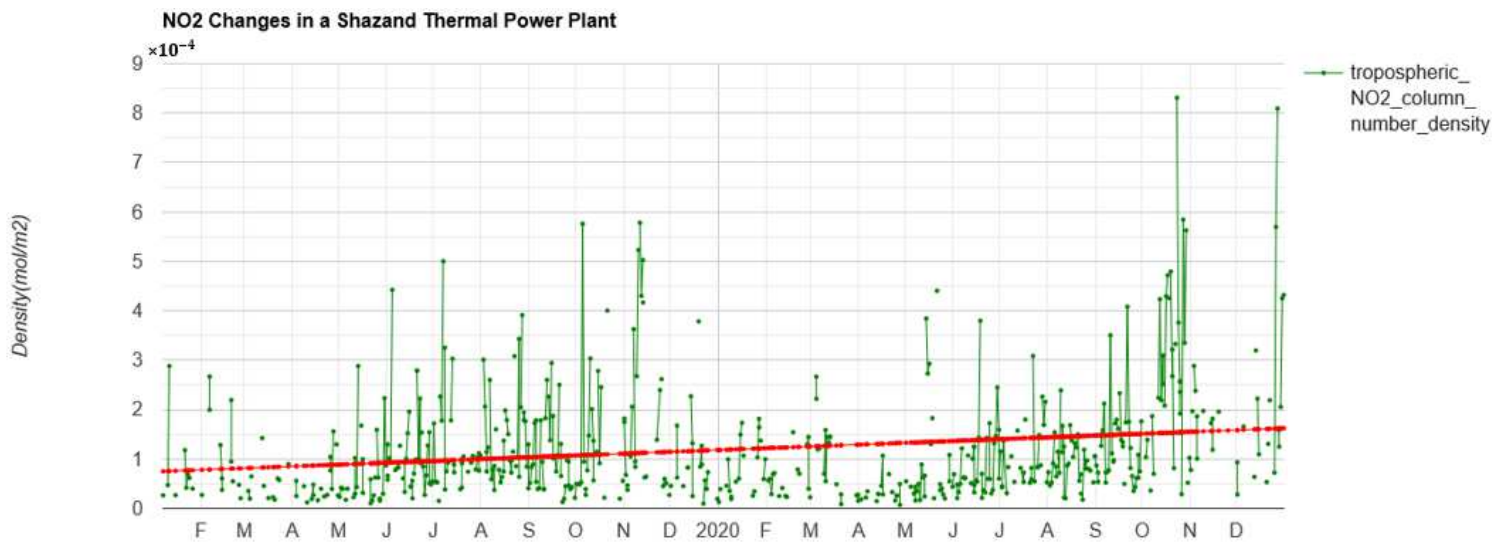

Fig 5 Trend of daily changes of tropospheric NO2 concentration in Shazand power plant from January 2019 to December 2020

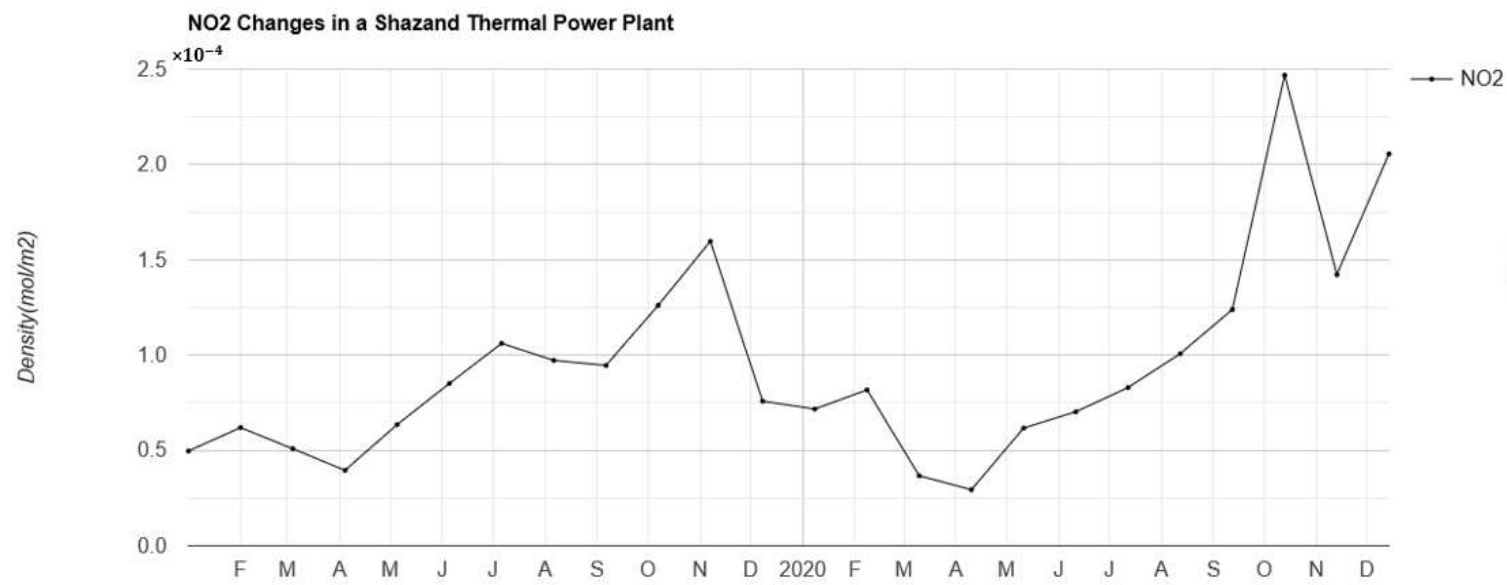

Fig 6 Trend of monthly changes of medians of tropospheric NO2 concentration Shazand thermal power plant from January 2019 to December 2020 
of the calibration process including the estimation of polynomial coefficients has been shown in Table 1. In order to evaluate how the proposed model fit to the observational data, a set of goodness-of-fit criteria including root mean square error (RMSE), mean absolute error (MAE) and correlation coefficient $\left(\mathrm{R}^{2}\right)$ are applied and the results have been summarized in Table 2 and Fig 7. As can be seen, the proposed model has been successful to fit observed data with the values of RMSE, MAE and $R^{2}$ equal to $2.1 \times 6-10,1.3 \times 6-10$ and 0.99 respectively.

Table 1 Coefficients of third-order rational equation between the concentration of $\mathrm{NO} 2$ in Arak city and its concentration in Shazand power plant

\begin{tabular}{|c|c|c|c|c|c|c|c|}
\hline$c_{0}$ & $c_{1}$ & $c_{2}$ & $c_{3}$ & $c_{4}$ & $c_{5}$ & $c_{6}$ & $c_{7}$ \\
\hline \hline $3.5 \times 10^{-3}$ & $4.5 \times 10^{-3}$ & $-5.8 \times 10^{-3}$ & $-2.6 \times 10^{-3}$ & $2.7 \times 10^{-3}$ & $-5.8 \times 10^{-4}$ & $4.5 \times 10^{-2}$ & $2.9 \times 10^{-5}$ \\
\hline$c_{8}$ & $c_{9}$ & $c_{10}$ & $c_{11}$ & $c_{12}$ & $c_{13}$ & $c_{14}$ & $c_{15}$ \\
\hline \hline $2.9 \times 10^{-3}$ & $-1.1 \times 10^{-2}$ & $6.3 \times 10^{-4}$ & $-2.2 \times 10^{-3}$ & $1.4 \times 10^{-5}$ & $2.8 \times 10^{-3}$ & $-8.8 \times 10^{-6}$ & $-1.8 \times 10^{-3}$ \\
\hline$c_{16}$ & $c_{17}$ & $c_{18}$ & $c_{19}$ & $c_{20}$ & $c_{21}$ & $c_{22}$ & $c_{23}$ \\
\hline \hline$-4 \times 10^{-7}$ & $-7.3 \times 10^{-4}$ & $1.5 \times 10^{-3}$ & $-4 \times 10^{-5}$ & $1.5 \times 10^{-4}$ & $-5.4 \times 10^{-3}$ & $-2.2 \times 10^{-5}$ & $-1.3 \times 10^{-3}$ \\
\hline$c_{24}$ & $c_{25}$ & $c_{26}$ & $c_{27}$ & $c_{28}$ & $c_{29}$ & $c_{30}$ & $c_{31}$ \\
\hline \hline$-2.4 \times 10^{-6}$ & $1.8 \times 10^{-6}$ & $-4.1 \times 10^{-7}$ & $-1.6 \times 10^{-4}$ & $-6.8 \times 10^{-5}$ & $2.6 \times 10^{-5}$ & $-4.2 \times 10^{-1}$ & $-3.7 \times 10^{-2}$ \\
\hline$c_{32}$ & $c_{33}$ & $c_{34}$ & $c_{35}$ & $c_{36}$ & $c_{37}$ & $c_{38}$ & $c_{39}$ \\
\hline \hline$-4.1 \times 10^{-3}$ & $2.7 \times 10^{-3}$ & $5.8 \times 10^{-2}$ & $-2.3 \times 10^{-2}$ & $3.8 \times 10^{-5}$ & $2.4 \times 10^{-3}$ & $1.9 \times 10^{-2}$ & $1 \times 10^{-3}$ \\
\hline$c_{40}$ & $c_{41}$ & $c_{42}$ & $c_{43}$ & $c_{44}$ & $c_{45}$ & $c_{46}$ & $c_{47}$ \\
\hline \hline$-5.4 \times 10^{-4}$ & $4.9 \times 10^{-6}$ & $2.4 \times 10^{-3}$ & $-2.6 \times 10^{-3}$ & $-1.1 \times 10^{-2}$ & $-3.3 \times 10^{-7}$ & $-9.1 \times 10^{-4}$ & $-2.6 \times 10^{-3}$ \\
\hline$c_{48}$ & $c_{49}$ & $c_{50}$ & $c_{51}$ & $c_{52}$ & $c_{53}$ & $c_{54}$ & $c_{55}$ \\
\hline \hline$-6.6 \times 10^{-5}$ & $1.6 \times 10^{-5}$ & $8 \times 10^{-3}$ & $-3.4 \times 10^{-5}$ & $-1 \times 10^{-3}$ & $-3.8 \times 10^{-6}$ & $1.5 \times 10^{-6}$ & $-2.3 \times 10^{-6}$ \\
\hline$c_{56}$ & $c_{57}$ & $c_{58}$ & & & & & \\
\hline$-3.1 \times 10^{-5}$ & $-1.5 \times 10^{-4}$ & $4.8 \times 10^{-5}$ & & & & & \\
\hline \hline
\end{tabular}

Table 2 Results of model fitness to control points

\begin{tabular}{|c|c|c|c|}
\hline Model & (MAE ) & (RMSE) & $\left.\mathbf{( R}^{2}\right)$ \\
\hline Third-order rational equation & $8.77 \times 10^{-9}$ & $1.23 \times 10^{-8}$ & 0.99 \\
\hline
\end{tabular}




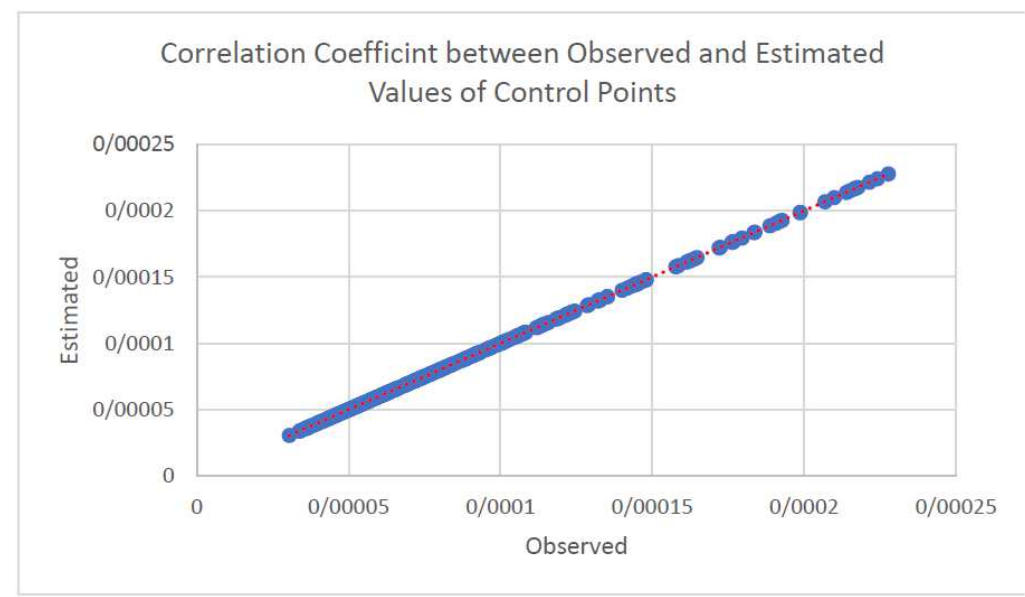

Fig 7 Correlation coefficient between estimated and observed values of NO2 at control points

Table 3 Results of model fitness to check points

\begin{tabular}{|c|c|c|c|}
\hline Model & (MAE ) & $(\mathbf{R M S E})$ & $\left.\mathbf{( R}^{\mathbf{2}}\right)$ \\
\hline Third-order rational equation & $1.06 \times 10^{-8}$ & $1.67 \times 10^{-8}$ & 0.99 \\
\hline
\end{tabular}

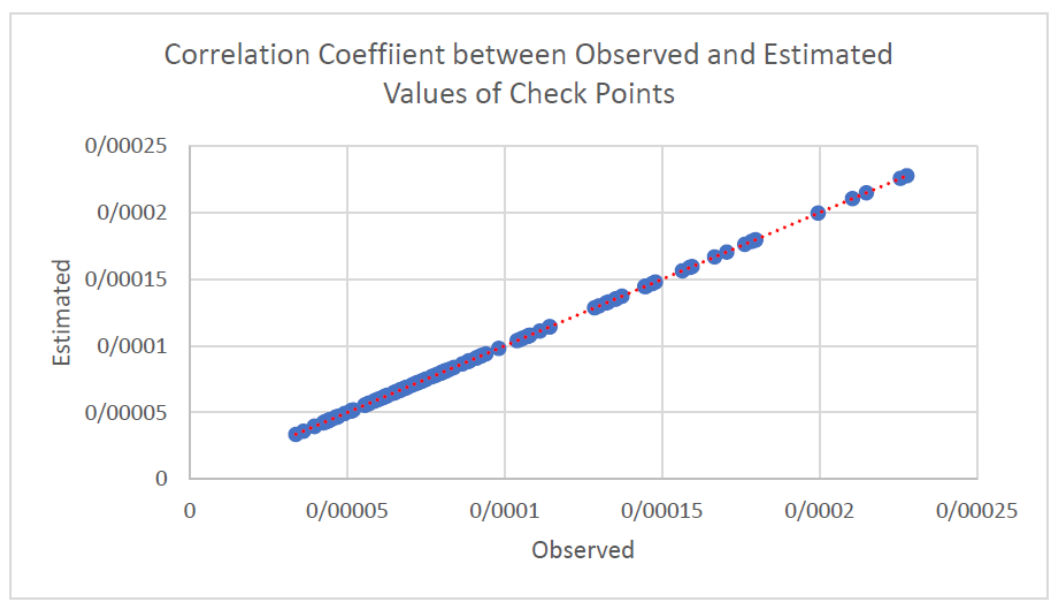

Fig 8 Correlation coefficient between estimated and observed values of NO2 at check points

The model validation has been carried out by applying five checkpoints as test data that were randomly distributed across the study area and were not included in the model calibration. Accordingly, the values of NO2 obtained from the model based on checkpoints have been monitored for 24 months (120 observations) and the results have been compared with the initial observed values (Table 3 and Fig 8). As can be seen, the values of RMSE, MAE and $\mathrm{R}^{2}$ equal to $1.7 \times{ }^{6-} 10,1.1 \times{ }^{6-} 10$ and 0.99 respectively indicates that the model not only fits the control points, but is able to be applied for check points that have not been participated in model calibration. As a result, the proposed model was able to create a good relationship between the concentration of $\mathrm{NO} 2$ generated in the Shazand power plant and the concentration of NO2 in Arak city at a specific time and place.

In general, industry plays an important role in polluting metropolitan areas (Prunet, Lezeaux et al. 2020). The distribution of nitrogen oxides (NOx) in urban areas and power plants is challenging issue (Goldberg, Lu et 
al. 2019). Therefore, it is possible to comprehend the importance of investigating the role of power plants in the process of air pollution. Determining that how different factors contribute in urban air pollution has been an important issue in many research (Baldasano 2020). In this research, the relationship between NO2 produced in Shazand power plant (as one of the main sources of air pollution in Arak) and its concentration over different parts of the study area has quantitatively been modeled. This numerical modeling can be applied in analyses of researchers and contribute to make better decisions to improve the air quality in our study area.

\section{Conclusion}

Nowadays, air pollution is considered as one of the main and most important challenging problems in Iran and in the world, which plays a critical role in climate change and human health. NO2 and NO (NOx) are known as toxic pollutants in the atmosphere and are produced when burning at high temperature and has negative effect on human repository system. Arak metropolitan area as an industrial city in Iran is always exposed to such pollutants and Shazand power plant is one of the main sources of producing NO2. Remote sensing technology and Sentinel-5 satellite image can be regarded as one of the most powerful tools for largescale pollution monitoring that can be applied to collect NO2 data pollution in our study area. The aim of this paper is to present a mathematical model to construct the relationship between concentration of NO2 in Shazand power plant and other locations at specific time over the study area and from the beginning of 2019 to the end of 2020. To investigate the trend of temporal and spatial changes of NO2 in the study area, 1460 images from the TROPOMI Sentinel-5 satellite sensor for the period from the beginning of 2019 to the end of 2020 have been used.

Results of monitoring shows that NO2 has been distributed from the power plant towards the center of the study area. To determine a mathematical model to relate the concentration of NO2 produced in Shazand power plant and different parts of the study area in both spatial and temporal dimension, a third-order rational equation has been proposed. The reason for choosing this equation is the flexibility of fractional equations in modeling complex phenomena compared to polynomial transformation equations. Therefore, a number of control points have been applied to determine the coefficients of the proposed model and also the evaluation of model has been conducted using check points. The results indicate that the concentration of NO2 obtained from the proposed model is consistent with the observed values. In order to evaluate whether the proposed model can be applied at other locations, the RMSE and MAE and $\mathrm{R}^{2}$ were applied and the results indicated that the model has been successful to model the relationships. Accordingly, it can be inferred that by monitoring NO2 in Shazand power plant, the amount of pollution in different parts of Arak can be estimated with acceptable accuracy. 


\section{Declarations}

\section{- Funding}

No funding was received for conducting this study.

\section{- Conflicts of interest/Competing interests}

The authors certify that they have NO affiliations with or involvement in any organization or entity with any financial interest (such as educational grants; participation in speakers' bureaus; membership, employment, consultancies, stock ownership, or other equity interest; and expert testimony or patent-licensing arrangements), or non-financial interest (such as personal or professional relationships, affiliations, knowledge or beliefs) in the subject matter or materials discussed in this manuscript

\section{- Availability of data and material (data transparency)}

Data needed for this study includes Sentinel-5, TROPOMI level-3 (L3) products which is available from Google Earth Engine: https://earthengine.google.com/

\section{- Code availability}

Not applicable' for that section.

\section{- Author's contribution}

All authors contributed to the study conception and design. Material preparation and data collection and analyses were performed by Mohammad Amin Ghannadi, Matin Shahri and Amir Reza Moradi. The first draft of the manuscript was written by Mohammad Amin Ghannadi and was edited by Matin Shahri. All authors commented on previous versions of the manuscript. All authors read and approved the final manuscript.

\section{- Ethics approval}

Hereby, authors consciously assure that for the manuscript "Modeling the Effect of Nitrogen Dioxide Produced in Shazand Power Plant upon Air Pollution in Arak, Iran Using Sentinel-5 Satellite data", the following is fulfilled:

1) This material is the authors' own original work, which has not been previously published elsewhere.

2) The paper is not currently being considered for publication elsewhere.

3) The paper reflects the authors' own research and analysis in a truthful and complete manner.

4) The paper properly credits the meaningful contributions of co-authors and co-researchers.

5) The results are appropriately placed in the context of prior and existing research.

6) All sources used are properly disclosed (correct citation).

7) All authors have been personally and actively involved in substantial work leading to the paper, and will take public responsibility for its content. 


\section{References}

Bai, X., H. Tian, X. Liu, B. Wu, S. Liu, Y. Hao, L. Luo, W. Liu, S. Zhao and S. Lin (2021). "Spatial-temporal variation characteristics of air pollution and apportionment of contributions by different sources in Shanxi province of China." Atmospheric Environment 244: 117926.

Baldasano, J. M. (2020). "COVID-19 lockdown effects on air quality by NO2 in the cities of Barcelona and Madrid (Spain)." Science of the Total Environment 741: 140353.

Bauwens, M., S. Compernolle, T. Stavrakou, J. F. Müller, J. Van Gent, H. Eskes, P. F. Levelt, R. van der A, J. Veefkind and J. Vlietinck (2020). "Impact of coronavirus outbreak on NO2 pollution assessed using TROPOMI and OMI observations." Geophysical Research Letters 47(11): e2020GL087978.

Caiazzo, F., A. Ashok, I. A. Waitz, S. H. Yim and S. R. Barrett (2013). "Air pollution and early deaths in the United States. Part I: Quantifying the impact of major sectors in 2005." Atmospheric Environment 79: 198208.

Cameletti, M. (2020). "The Effect of Corona Virus Lockdown on Air Pollution: Evidence from the City of Brescia in Lombardia Region (Italy)." Atmospheric Environment 239: 117794.

Chowdhury, S. and S. Dey (2016). "Cause-specific premature death from ambient PM2. 5 exposure in India: Estimate adjusted for baseline mortality." Environment international 91: 283-290.

de Vries, J., R. Voors, B. Ording, J. Dingjan, P. Veefkind, A. Ludewig, Q. Kleipool, R. Hoogeveen and I. Aben (2016). TROPOMI on ESA's Sentinel $5 p$ ready for launch and use. Fourth International Conference on Remote Sensing and Geoinformation of the Environment (RSCy2016), International Society for Optics and Photonics.

Dickerson, R. R., D. C. Anderson and X. Ren (2019). "On the use of data from commercial NOx analyzers for air pollution studies." Atmospheric Environment 214: 116873.

Finney, D., R. Doherty, O. Wild, P. J. Young and A. Butler (2016). "Response of lightning NO x emissions and ozone production to climate change: Insights from the Atmospheric Chemistry and Climate Model Intercomparison Project." Geophysical Research Letters 43(10): 5492-5500.

Ghude, S. D., D. Chate, C. Jena, G. Beig, R. Kumar, M. Barth, G. Pfister, S. Fadnavis and P. Pithani (2016). "Premature mortality in India due to PM2. 5 and ozone exposure." Geophysical Research Letters 43(9): 46504658.

Goldberg, D. L., Z. Lu, D. G. Streets, B. de Foy, D. Griffin, C. A. McLinden, L. N. Lamsal, N. A. Krotkov and H. Eskes (2019). "Enhanced Capabilities of TROPOMI NO2: Estimating NO X from North American Cities and Power Plants." Environmental science \& technology 53(21): 12594-12601.

Grewe, V., K. Dahlmann, S. Matthes and W. Steinbrecht (2012). "Attributing ozone to NOx emissions: Implications for climate mitigation measures." Atmospheric environment 59: 102-107.

Hedelt, P., D. S. Efremenko, D. G. Loyola, R. Spurr and L. Clarisse (2019). "Sulfur dioxide layer height retrieval from Sentinel-5 Precursor/TROPOMI using FP_ILM." Atmospheric Measurement Techniques 12(10).

Ialongo, I., H. Virta, H. Eskes, J. Hovila and J. Douros (2020). "Comparison of TROPOMI/Sentinel-5 Precursor NO2 observations with ground-based measurements in Helsinki." Atmospheric Measurement Techniques 13(1).

Kampa, M. and E. Castanas (2008). "Human health effects of air pollution." Environmental pollution 151(2): 362-367.

Kim, S. W., A. Heckel, S. McKeen, G. Frost, E. Y. Hsie, M. Trainer, A. Richter, J. Burrows, S. Peckham and G. Grell (2006). "Satellite-observed US power plant NOx emission reductions and their impact on air quality." Geophysical Research Letters 33(22).

Lelieveld, J., J. S. Evans, M. Fnais, D. Giannadaki and A. Pozzer (2015). "The contribution of outdoor air pollution sources to premature mortality on a global scale." Nature 525(7569): 367-371.

Lorente, A., K. Boersma, H. Eskes, J. Veefkind, J. Van Geffen, M. de Zeeuw, H. D. van der Gon, S. Beirle and M. Krol (2019). "Quantification of nitrogen oxides emissions from build-up of pollution over Paris with TROPOMI." Scientific reports 9(1): 1-10.

Mesas-Carrascosa, F.-J., F. Pérez Porras, P. Triviño-Tarradas, A. García-Ferrer and J. E. Meroño-Larriva (2020). "Effect of lockdown measures on atmospheric nitrogen dioxide during SARS-CoV-2 in Spain." Remote Sensing 12(14): 2210. 
Ogen, Y. (2020). "Assessing nitrogen dioxide (NO2) levels as a contributing factor to the coronavirus (COVID-19) fatality rate." Science of The Total Environment: 138605.

Omrani, H., B. Omrani, B. Parmentier and M. Helbich (2020). "Spatio-temporal data on the air pollutant nitrogen dioxide derived from Sentinel satellite for France." Data in brief 28: 105089.

Park, J., M. Shin, J. Lee and J. Lee (2020). "Estimating the effectiveness of vehicle emission regulations for reducing NOx from light-duty vehicles in Korea using on-road measurements." Science of The Total Environment: 144250.

Prunet, P., O. Lezeaux, C. Camy-Peyret and H. Thevenon (2020). "Analysis of the NO2 tropospheric product from S5P TROPOMI for monitoring pollution at city scale." City and Environment Interactions 8: 100051. Quesada-Ruiz, S., J.-L. Attié, W. A. Lahoz, R. Abida, P. Ricaud, L. E. Amraoui, R. Zbinden, A. Piacentini, M. Joly and H. Eskes (2020). "Benefit of ozone observations from Sentinel-5P and future Sentinel-4 missions on tropospheric composition." Atmospheric Measurement Techniques 13(1): 131-152.

Safarianzengir, V., B. Sobhani, M. H. Yazdani and M. Kianian (2020). "Monitoring, analysis and spatial and temporal zoning of air pollution (carbon monoxide) using Sentinel-5 satellite data for health management in Iran, located in the Middle East." AIR QUALITY ATMOSPHERE AND HEALTH.

Saxena, P. and V. Naik (2018). Air pollution: sources, impacts and controls, CABI.

Shikwambana, L., P. Mhangara and N. Mbatha (2020). "Trend analysis and first time observations of sulphur dioxide and nitrogen dioxide in South Africa using TROPOMI/Sentinel-5 P data." International Journal of Applied Earth Observation and Geoinformation 91: 102130.

Sohn, H. G., C. H. Park and H. Chang (2005). "Rational function model-based image matching for digital elevation models." The Photogrammetric Record 20(112): 366-383.

Stratoulias, D. and N. Nuthammachot (2020). "Air quality development during the COVID-19 pandemic over a medium-sized urban area in Thailand." Science of The Total Environment 746: 141320.

Theys, N., P. Hedelt, I. De Smedt, C. Lerot, H. Yu, J. Vlietinck, M. Pedergnana, S. Arellano, B. Galle and D. Fernandez (2019). "Global monitoring of volcanic SO 2 degassing with unprecedented resolution from TROPOMI onboard Sentinel-5 Precursor." Scientific reports 9(1): 1-10.

Vîrghileanu, M., I. Săvulescu, B.-A. Mihai, C. Nistor and R. Dobre (2020). "Nitrogen Dioxide (NO2) Pollution Monitoring with Sentinel-5P Satellite Imagery over Europe during the Coronavirus Pandemic Outbreak." Remote Sensing 12(21): 3575. 


\section{Figures}

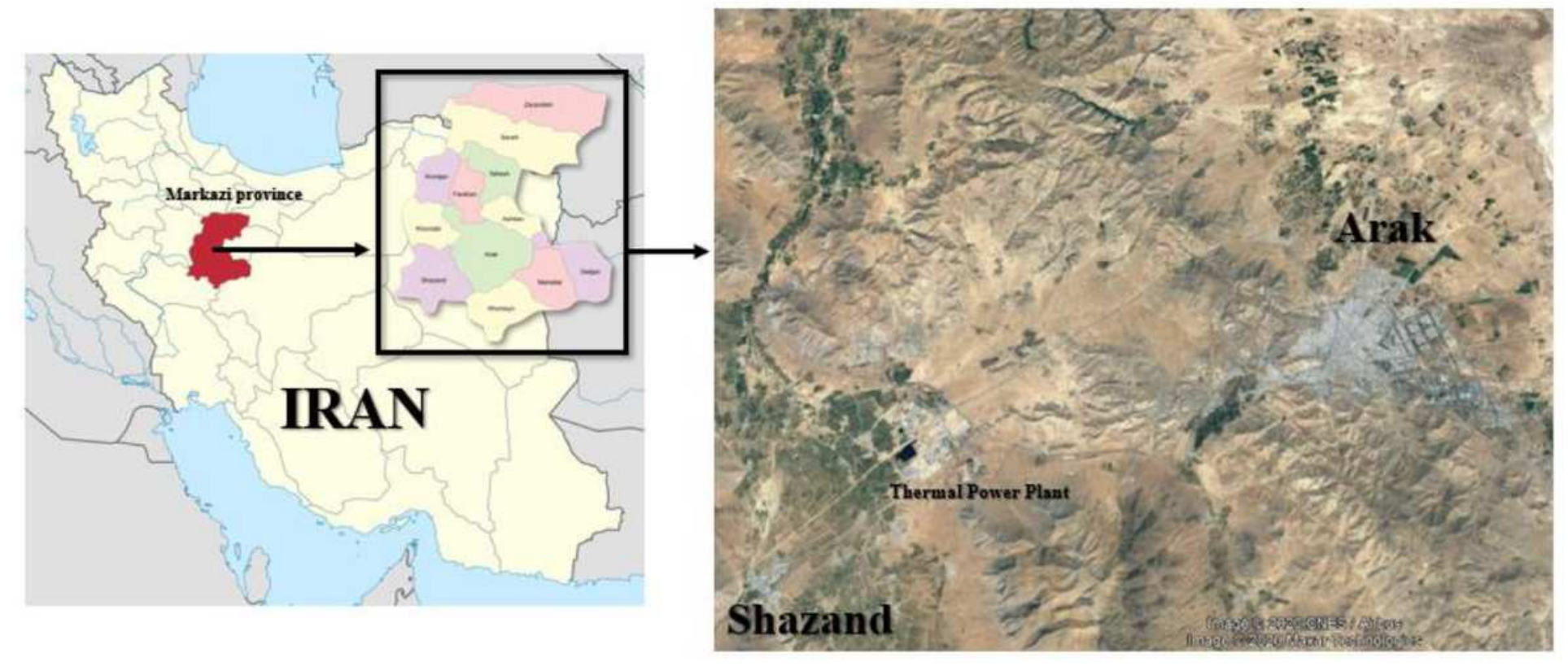

\section{Figure 1}

Overview of Study area, Arak, Markazi Province, Iran Note: The designations employed and the presentation of the material on this map do not imply the expression of any opinion whatsoever on the part of Research Square concerning the legal status of any country, territory, city or area or of its authorities, or concerning the delimitation of its frontiers or boundaries. This map has been provided by the authors. 


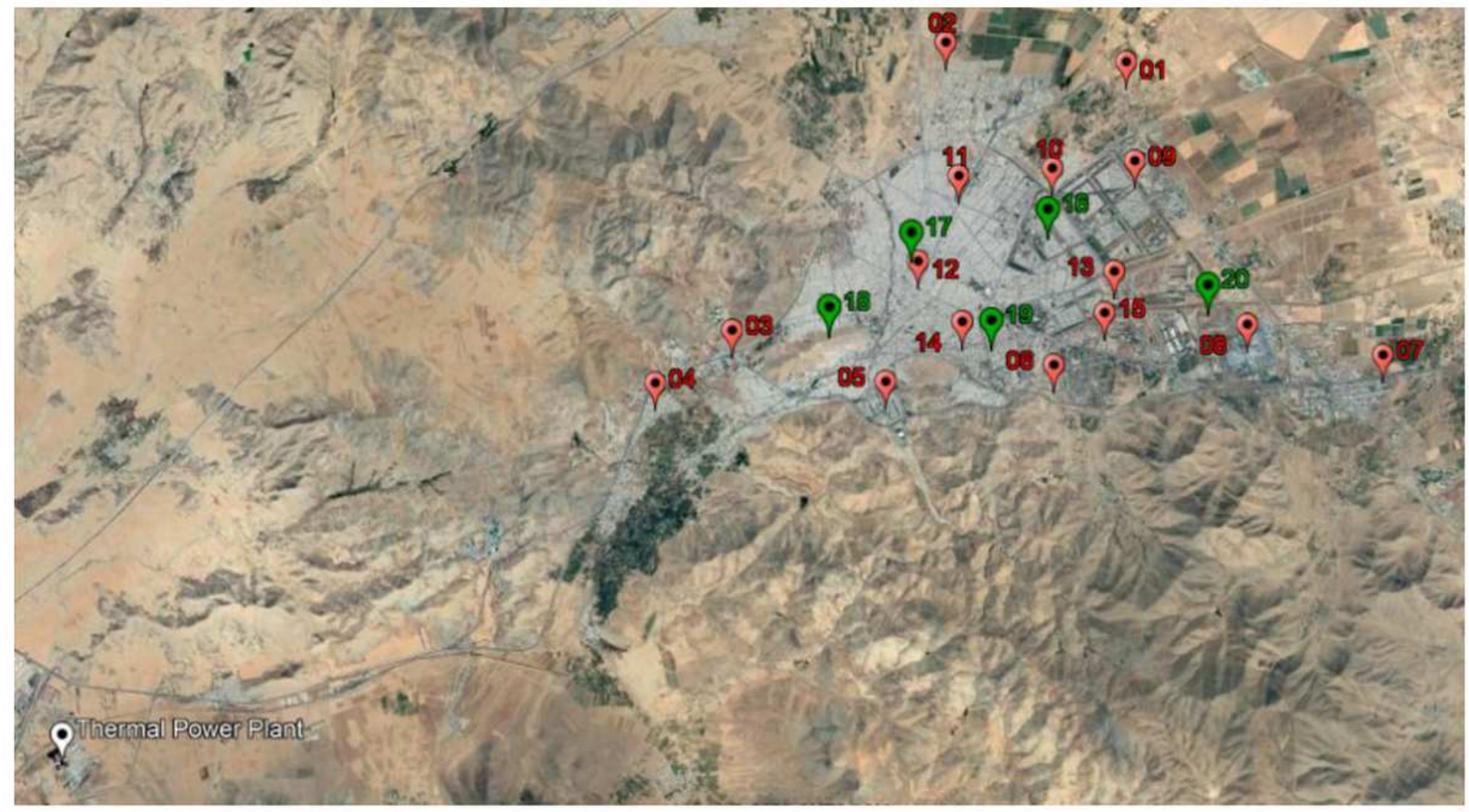

Figure 2

Spatial distribution of control and check points in the study area. Note: The designations employed and the presentation of the material on this map do not imply the expression of any opinion whatsoever on the part of Research Square concerning the legal status of any country, territory, city or area or of its authorities, or concerning the delimitation of its frontiers or boundaries. This map has been provided by the authors. 


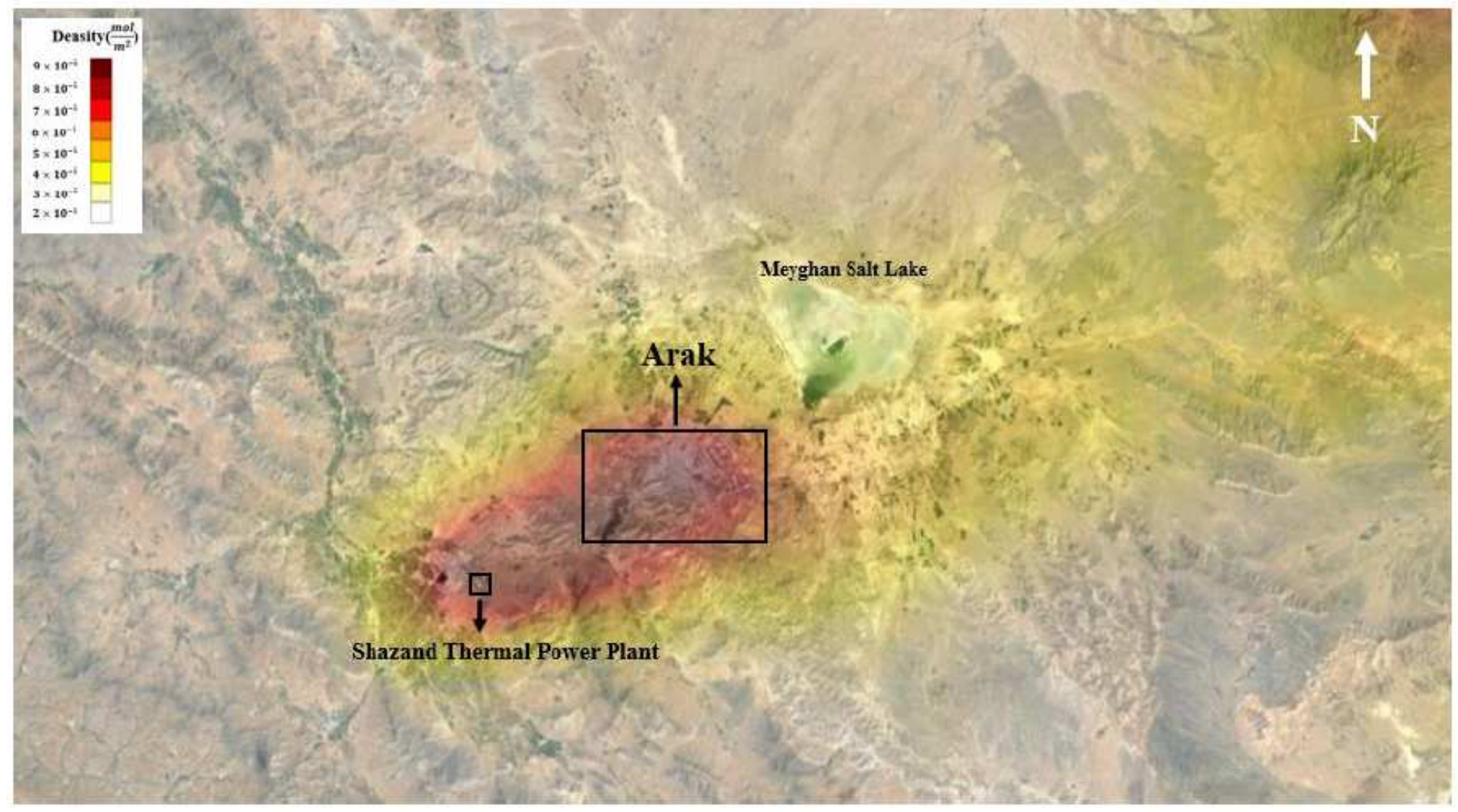

\section{Figure 3}

Variation of tropospheric NO2 distribution in the study area from January 2019 to December 2020 Note: The designations employed and the presentation of the material on this map do not imply the expression of any opinion whatsoever on the part of Research Square concerning the legal status of any country, territory, city or area or of its authorities, or concerning the delimitation of its frontiers or boundaries. This map has been provided by the authors. 

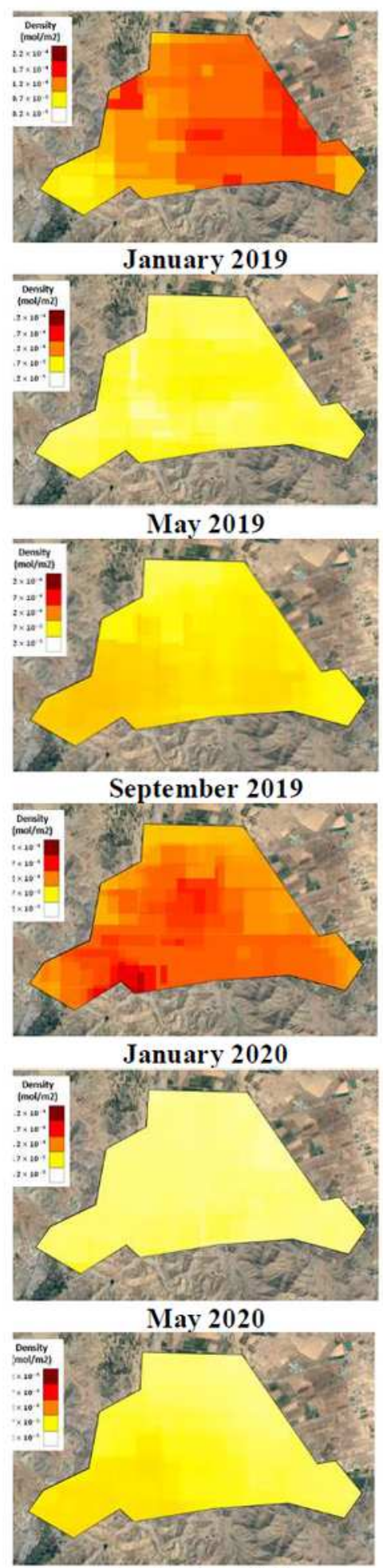

September 2020

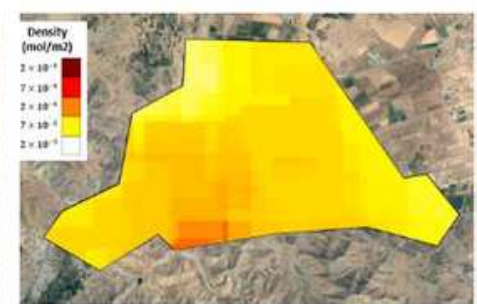

February 2019

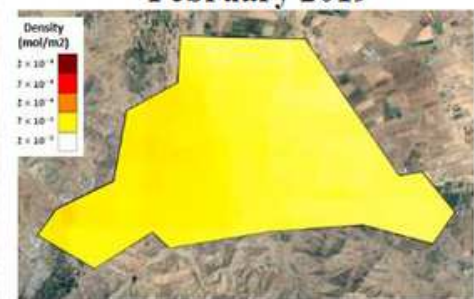

June 2019

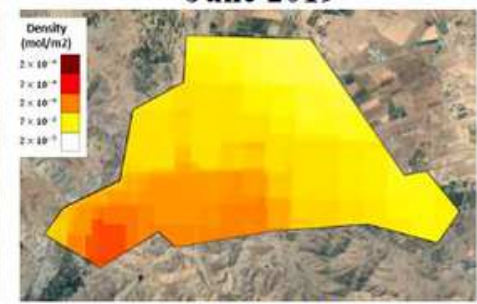

October 2019

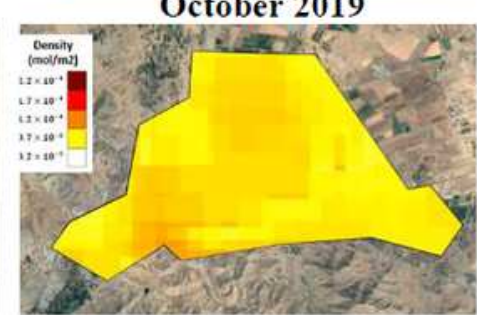

February 2020

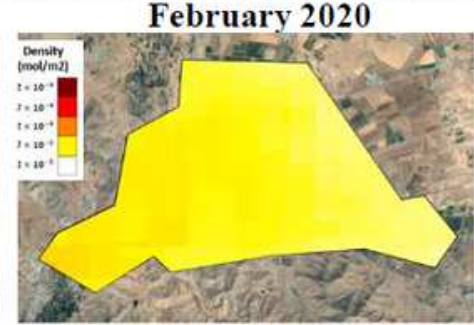

June 2020

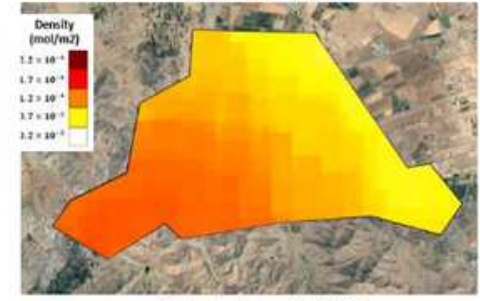

October 2020
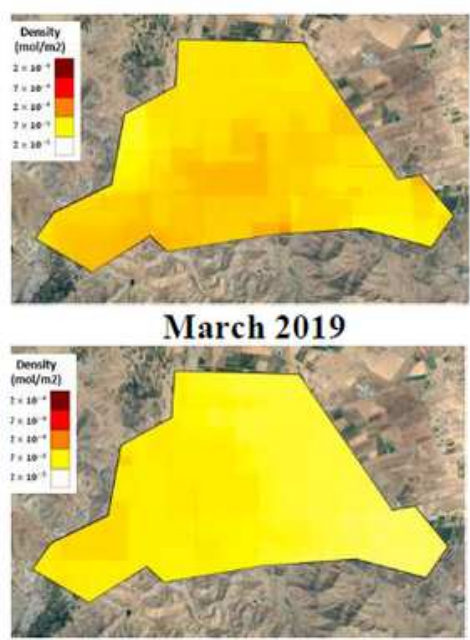

July 2019

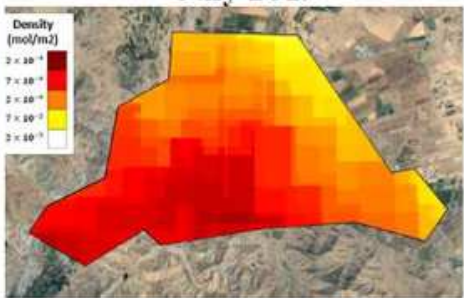

November 2019
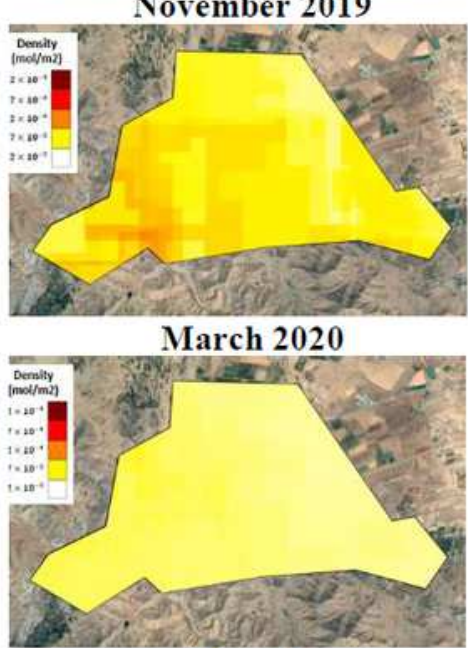

July 2020

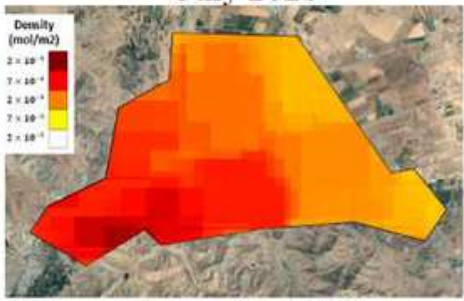

November 2020

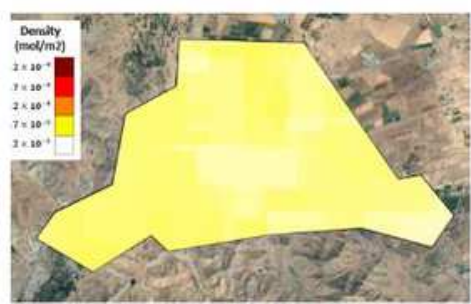

April 2019

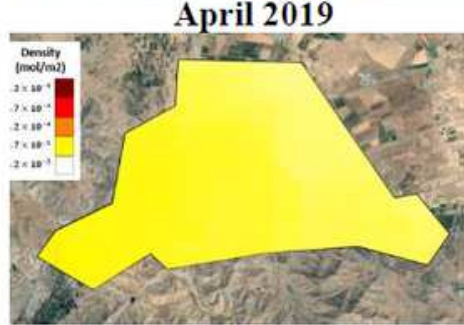

August 2019

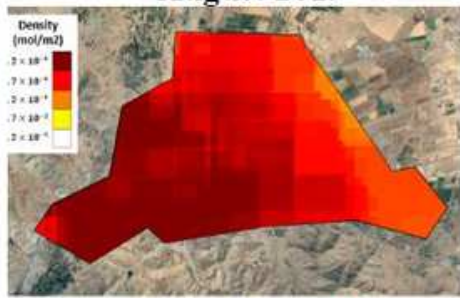

December 2019

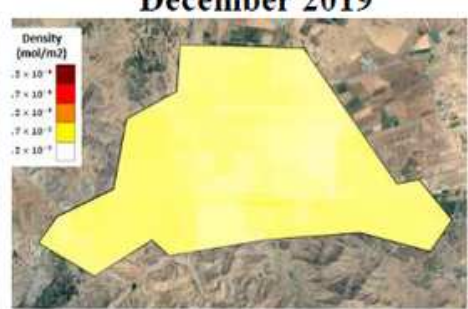

April 2020

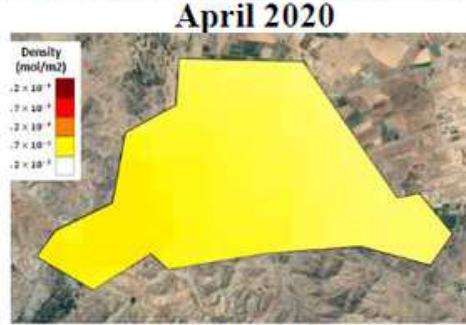

August 2020

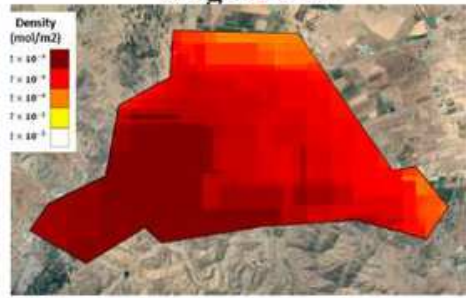

December 2020

\section{Figure 4}

The trend of spatial variation of concentration of NO2 in Arak from January 2019 to December 2020 


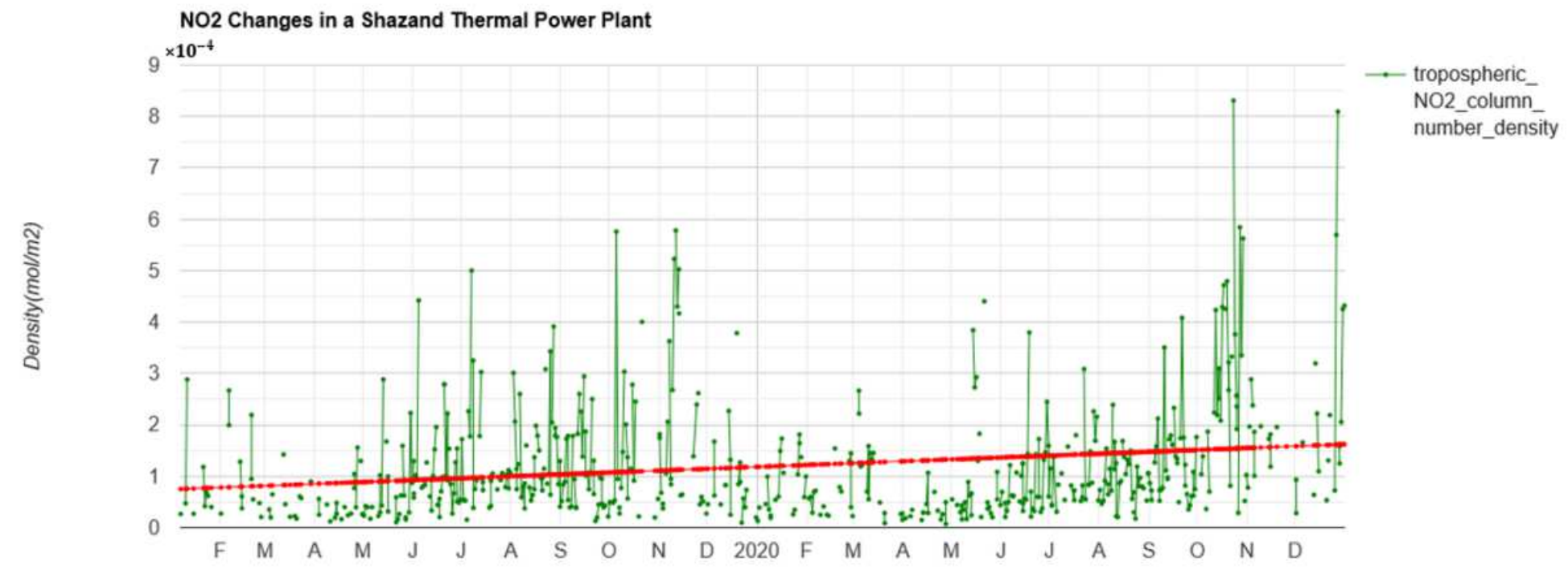

Figure 5

Trend of daily changes of tropospheric NO2 concentration in Shazand power plant from January 2019 to December 2020

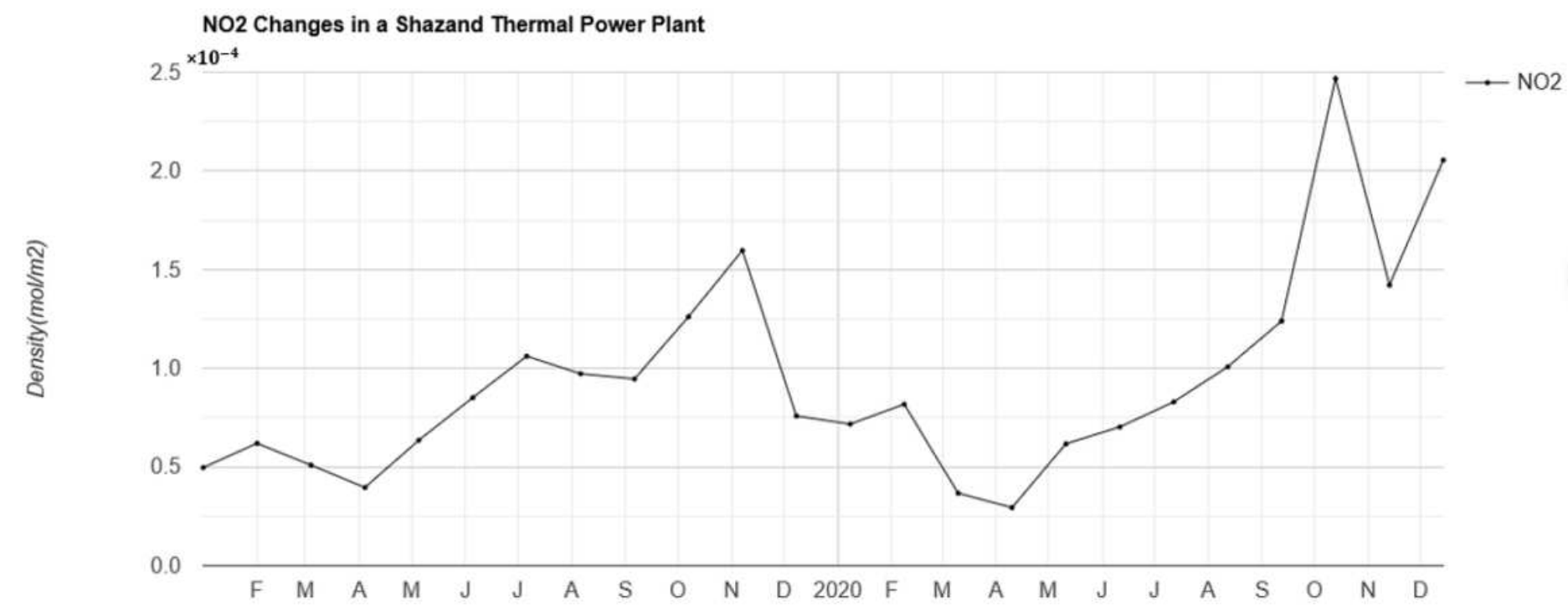

\section{Figure 6}

Trend of monthly changes of medians of tropospheric NO2 concentration Shazand thermal power plant from January 2019 to December 2020 


\section{Correlation Coefficint between Observed and Estimated Values of Control Points}

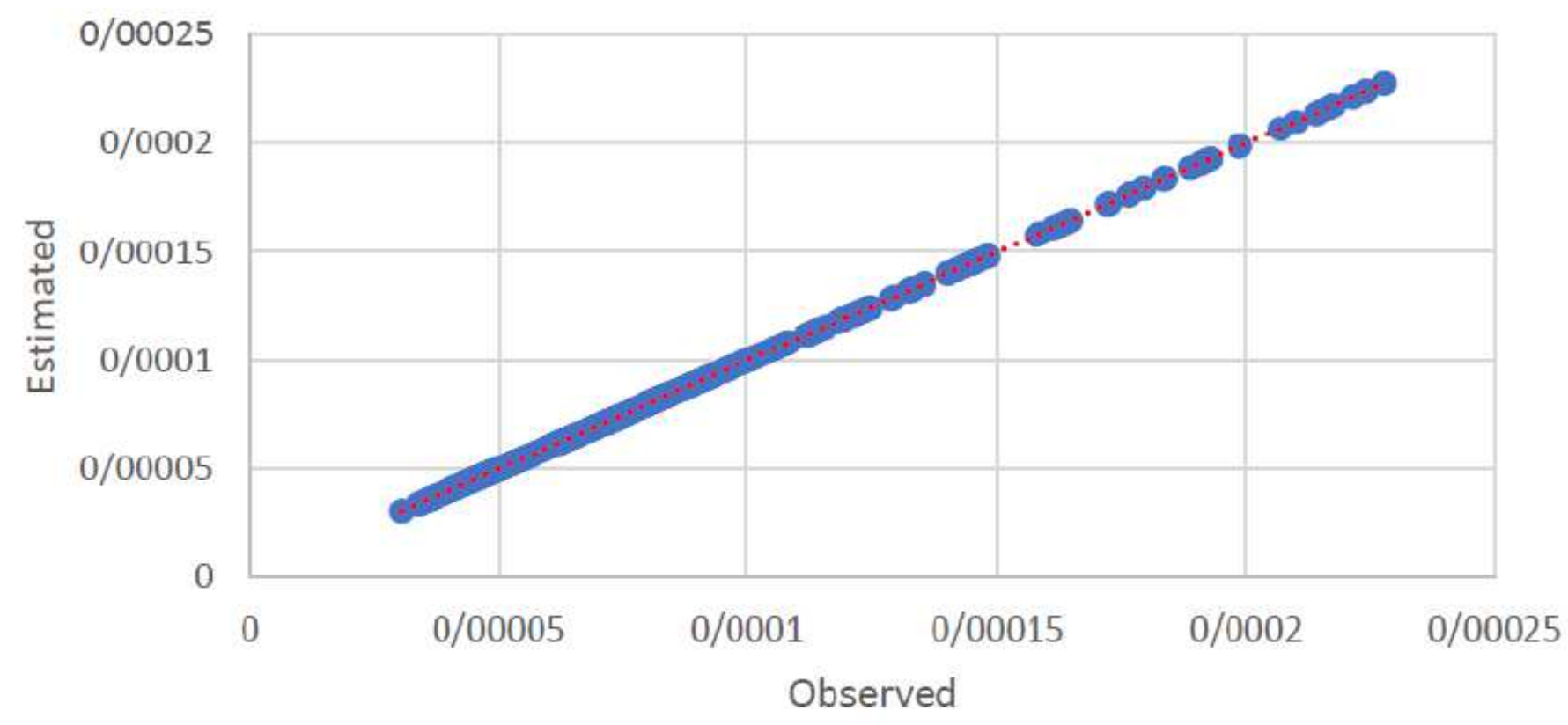

Figure 7

Correlation coefficient between estimated and observed values of NO2 at control points

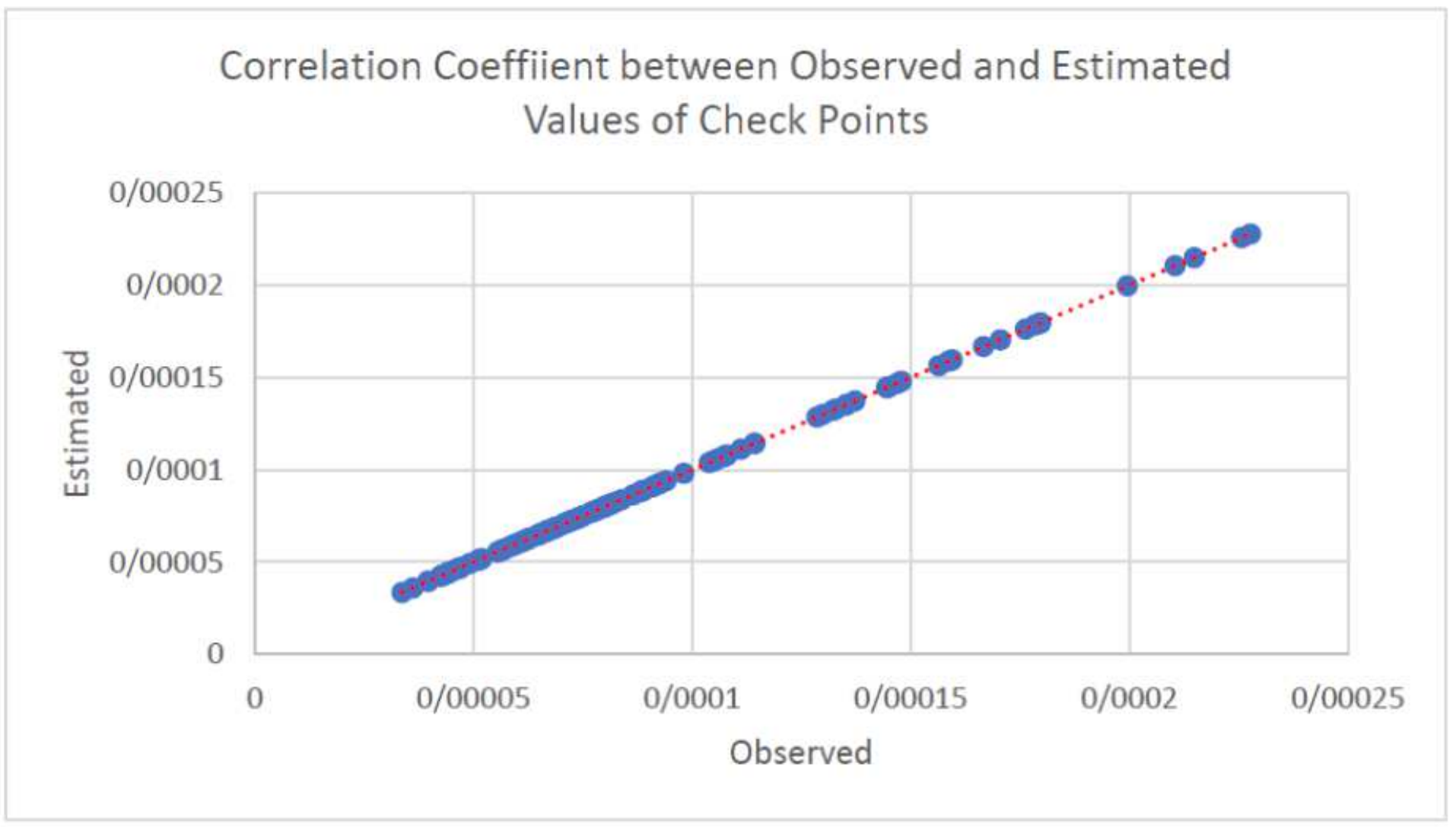


Figure 8

Correlation coefficient between estimated and observed values of NO2 at check points 